\title{
Trends in Under-5 Mortality Rates and Their Associations with Socioeconomic Factors Among Countries Participating in the Belt and Road Initiative: A Panel Data Analysis
}

\author{
Ruhai Bai (D) \\ Wanyue Dong ${ }^{2}$ \\ Jinli $\mathrm{Liu}^{3}$ \\ Qiao Peng ${ }^{3}$ \\ Jun Lyu $\mathbb{D}^{4}$
}

'School of Public Affairs, Nanjing University of Science and Technology, Nanjing, People's Republic of China; ${ }^{2}$ School of Health Economics and Management, Nanjing University of Chinese Medicine, Nanjing, People's Republic of China; ${ }^{3}$ Health Science Center, Xi'an Jiaotong University, Xi'an, People's Republic of China; ${ }^{4}$ Department of Clinical Research, The First Affiliated Hospital of Jinan University, Guangzhou, People's Republic of China
Correspondence: Jun Lyu Department of Clinical Research, The First Affiliated Hospital of Jinan University, No. 60I, West Huangpu Avenue, Guangzhou, Guangdong, People's Republic of China

Email lyujun2020@jnu.edu.cn
Purpose: The Belt and Road Initiative (BRI) provided a platform to promote trade and economic collaboration, with health promotion also being an important component. This study examined the burden of the under-5 mortality rate (U5MR) among BRI countries and studied the impact of socioeconomic development on the U5MR.

Patients and Methods: Data were collected from 137 BRI countries for the period 2000 2018. The temporal changes in the U5MR and the estimated annual percentage change (EAPC) were used to assess the U5MR burden. A quantile fixed-effects model was used to access the associations between socioeconomic factors and the U5MR.

Results: The U5MR varied widely among the 137 analyzed countries in 2018, being highest in Somalia (121.5 per 1000) and lowest in Slovenia (2.1 per 1000). The decreasing trend in U5MR was largest in Montenegro $(\mathrm{EAPC}=-9.6,95 \%$ confidence interval $[\mathrm{CI}]=-10.2$ to -9.0 ), while the increasing trend was largest in Dominica (EAPC $=6.0,95 \% \mathrm{CI}=5.3$ to 6.7). Countries with higher U5MRs in 2000 experienced more rapid decreases in the U5MR from 2000 to 2018. The influence of socioeconomic factors on U5MR was related to the distribution of U5MR.

Conclusion: The U5MR remains a major public-health issue in some BRI countries. Improving the economic situation will benefit child health in BRI countries in the long run. Keywords: Belt and Road, under-five mortality rate, socioeconomic, economic factors

\section{Introduction}

Reducing child mortality has received considerable international attention over the past few decades, with the United Nations setting reducing child mortality as an important aspect of the Sustainable Development Goals (SDG). The SDG require all countries to reduce the under-5 mortality rate (U5MR) to no more than 25 per 1000 live births by $2030 .{ }^{1}$ Child mortality has been decreasing both worldwide and in many individual countries for decades. ${ }^{2}$ However, the progress has been uneven, and high child mortality rates persist in many countries. ${ }^{3}$ Since some countries may still experience difficulties in reaching the SDG, more efforts are needed to decrease child mortality globally.

In 2013, China launched the Belt and Road Initiative (BRI) to promote trade, infrastructure, and commercial associations across countries in Asia, Africa, and Europe. $^{4-6}$ The BRI is an important development initiative that provided a platform 
for cooperation in many fields - including public healthfor the participating countries, and the aims of the BRI are consistent with the SDG. ${ }^{7}$ Besides the direct assistance to related countries in the health field, ${ }^{5}$ the improvements in the economic situation associated with the BRI may change in the involved regions, ${ }^{6}$ and such changes in the economic situation may impact child health. ${ }^{8}$ However, few studies described the status of U5MR in BRI countries and explore the impact of macroeconomic changes on U5MR in these countries. To inform planning for future health and social services collaborations, it is important to assess the U5MR and how economic changes affect the health status of children.

Since the 1980s, a number of quantitative studies have attempted to explore the global determinants of U5MR. ${ }^{9}$ They provided strong insights into the correlation of socioeconomic factors on mortality levels in under $5 \mathrm{~s} .^{9-11}$ The improved economic situation may contribute to raising living standards and the ability to devote more resources to areas like health care and education, which would effectively decrease child mortality. ${ }^{12}$

Even previous studies provided important information on relationships between socioeconomic factors and child mortality, their results do not give a full picture of the relationship between explanatory and outcome variables. Those studies only described the conditional mean of an outcome without describing the scale of its distribution, which may lead to a loss of information. ${ }^{6}$ In this study, we used the quantile fixed-effects model, which would provide a complete image of the effects of covariates on U5MR by estimating the family of conditional quantile function, making quantile fixed-effects model a natural choice for this analysis due to their robustness and lack of distribution hypothesis. ${ }^{13}$

This study therefore conducted into two main parts. In the first part, we documented the temporal trends in the U5MR and examined the correlation between the annual percentage change of U5MR and the baseline U5MR among BRI countries. In the second part, we accessed the impact of macroeconomic changes on the U5MR in BRI countries.

This study hypothesized that U5MR would correlate with socioeconomic factors such as the gross domestic product (GDP) per capita, annual percentage growth rate of GDP, inflation and unemployment rate, all of which have significant impacts on the daily life of the population. Our findings will help to improve the understanding of the U5MR burden among BRI countries as well as the impact of the economic situation on child health. The results will facilitate the development of effective prevention strategies for child health under the BRI.

\section{Materials and Methods Data Sources}

By the end of January 2020, 137 countries had signed the cooperation document on the BRI. ${ }^{14}$ The present study collected data on BRI countries from World Health Organization (WHO) and World Bank Databank databases. The study did not report any individual information regarding any human or animal samples, so ethical approval was not required.

The U5MR equates to the probability per 1000 of a newborn baby dying before reaching the age of 5 years, is one of the key indicators of global health. ${ }^{15}$ To quantify the association of mortality in U5MR with socioeconomic factors, according to the literature, ${ }^{16}$ we selected four main socioeconomic factors as independent variables (the gross domestic product (GDP) per capita, annual percentage growth rate of GDP, inflation, and unemployment rate).

The literature review indicated a negative correlation between income and child mortality. ${ }^{17}$ GDP per capita is an important indicator of a country's income, ${ }^{18}$ thus, we used GDP per capita as a measure of the population's income. The GDP per capita is the GDP divided by midyear population, with the GDP being the sum of the gross value contributed by all resident producers in the economy plus any product taxes, and minus any subsidies not included in the value of the products. The GDP is calculated without making deductions for depreciation of fabricated assets or for the depletion and degradation of natural resources. In this study, the GDP values (including aggregated values) were calculated as the equivalent US dollar values in 2010. The impact of the economic recessions on child mortality has been reported to be pervasive. ${ }^{8,19} \mathrm{We}$ used the annual percentage growth rate of GDP capturing the population's economic situation. ${ }^{20}$ Parental employment state was proved to have a certain impact on child health. ${ }^{21}$ In this study, we used unemployment rate to reflect employment state of the population. The unemployment rate refers to the share of the labor force that is without work but is available for and seeking employment. Fluctuate of food price would have a certain impact on undernourishment, ${ }^{22}$ and thus leading to an increase in infant and child mortality. ${ }^{23}$ In this study, we used inflation 
to capture the fluctuation of price. Inflation as measured by the annual growth rate of the GDP implicit deflator reflects the rate at which price changes in the economy as a whole. All these variables are aspects of the economic situation that have significant impacts on daily lives among the population and especially of vulnerable groups. ${ }^{16}$

\section{Statistical Analysis}

The trends in the U5MR were quantified using the estimated annual percentage change (EAPC). The EAPC is a widely used summary measure of the trend over a specified interval. ${ }^{24} \mathrm{~A}$ linear regression model was fitted to the natural logarithm of the U5MR; that is, $y=\alpha+\beta x+\varepsilon$, where $y=\ln (U 5 M R)$ and $x=$ calendar year. The EAPC was calculated as $100 \times(\exp (\beta)-1)$, and its $95 \%$ confidence interval $(\mathrm{CI})$ can be obtained from a linear regression model. $^{24}$

Pearson's product-moment correlation was used to access the correlation between EAPC and U5MR in 2000 among BRI countries. This will help understand the relationship between U5MR levels in 2000 and the magnitude of U5MR change.

A quantile fixed-effects model was used to assess the impact of socioeconomic factors on different quantiles of the U5MR. The main advantage of such a model over simple regression methods is that it extends regression for modeling the mean to analyzing the entire conditional distribution of the outcome variable. ${ }^{13}$ In addition, unlike ordinary linear regression, quantile regression does not require any assumption about the distribution of the regression residuals, and is very robust at dealing with outliers and skewed distributions. ${ }^{25}$ Therefore, by consideration of the shape, scale, and location of the distribution, quantile models can provide a complete picture of the distributional effects.

We implemented the quantile fixed-effects models using the U5MR as a dependent variable, country as a categorical variable, and the socioeconomic variables (ie, GDP per capita, inflation, annual percentage growth rate of GDP, and unemployment rate) as continuous predictors. GDP per capita was divided by 1000 to facilitate the interpretation of the obtained results. Five quantiles of U5MR were selected (10th, 25th, 50th, 75th, 90th) from lowest to highest U5MR in BRI countries, which would provide a picture of the distributional effects. Due to limitations of the available data for some socioeconomic variables, we used data from 2000 to 2016 to fit the regression model. There were missing data for the following countries, which were therefore excluded from the regression analysis: Afghanistan, Antigua and Barbuda, Djibouti, Dominica, Grenada, Kiribati, Liberia, Micronesia, Montenegro, Qatar, Seychelles, Somalia, South Sudan, and Timor-Leste. This study used a fixedeffects model to provide a basis comparison with the quantile fixed-effects model.

Figure 1 shows the flow chart presenting the procedures of this study. The downloaded data were imported into Microsoft Excel and subsequently analyzed using $\mathrm{R}$ statistical software (version 3.6.3, R Foundation for Statistical Computing, Vienna, Austria). The fixed-effects and quantile fixed-effects models were developed using the "plm" and "rqpd" packages, respectively. A $p$ value of $<0.05$ was considered indicative of statistical significance.

\section{Results \\ Changes in U5MR Among BRI Countries from 2000 to 2018}

The U5MR varied widely among the 137 analyzed countries in 2018 (Figure 2A), ranging from 121.5 per 1000 in Somalia to 2.1 per 1000 in Slovenia. The ten BRI countries with the highest U5MRs in 2018 were all in subSaharan Africa. The U5MR in 2018 in 59 BRI countries was higher than 25 per 1000 live births, which was the upper limit of the U5MR in the SDG to be achieved by 2030. The U5MR in 2018 was lower than 10 per 1000 live births in 46 BRI countries.

The decrease in the U5MR from 2000 to 2018 was largest in Rwanda (183.1 to 35.3 per 1000), followed by Niger (226.1 to 83.7 per 1000) and Sierra Leone (234.0 to 105.1 per 1000). The U5MR increased from 2000 to 2018 in five BRI countries, with this increase being largest in Dominica (14.8 to 35.7 per 1000), followed by Fiji (22.7 to 25.6 per 1000), Venezuela (21.6 to 24.5 per 1000), Brunei (10.3 to 11.6 per 1000), and Seychelles (13.7 to 14.5 per 1000) (Figure 2B).

The decreasing trend in the U5MR across the $137 \mathrm{BRI}$ countries was largest in Montenegro $(\mathrm{EAPC}=-9.6,95 \%$ $\mathrm{CI}=-10.2$ to -9.0$)$, followed by Rwanda $(\mathrm{EAPC}=-9.3$, $95 \% \mathrm{CI}=-9.7$ to -8.8$)$ and Kazakhstan $(\mathrm{EAPC}=-8.4$, $95 \% \mathrm{CI}=-8.7$ to -8.0$)$. The increasing trend in the U5MR was largest in Dominica $(\mathrm{EAPC}=6.0,95 \%$ $\mathrm{CI}=5.3$ to 6.7$)$, followed by Brunei $(\mathrm{EAPC}=0.8,95 \%$ $\mathrm{CI}=0.4$ to 1.3$)$ and Fiji $(\mathrm{EAPC}=0.7,95 \% \mathrm{CI}=0.6$ to 0.8 ) (Figure 2C). 


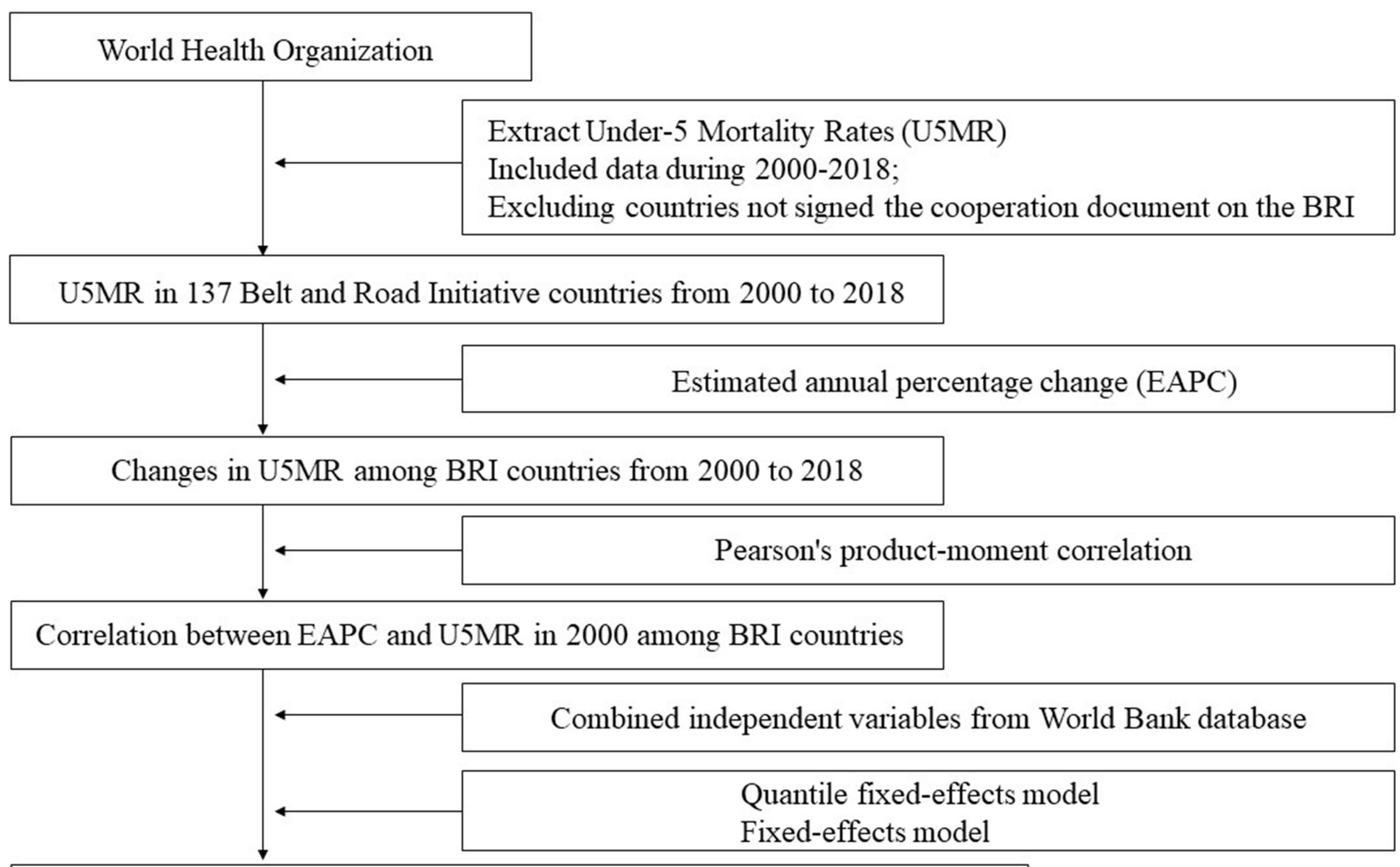

Associations between U5MR and socioeconomic factors among BRI countries

Figure I Study flowchart.

\section{Correlation Between EAPC and U5MR in 2000 Among BRI Countries}

Figure 3 shows that a significant negative correlation was detected between the EAPC and U5MR in $2000(\rho=-$ $2.218, p<0.05)$. The U5MR in 2000 reflects the child death rate at baseline in each country, and countries with higher U5MRs in 2000 experienced more-rapid decreases in the U5MR from 2000 to 2018.

\section{Associations Between U5MR and Socioeconomic Factors Among BRI Countries}

The quantile regression analyses suggested the presence of inconsistencies in the associations between the U5MR and socioeconomic factors across quantiles (Table 1). Figure 4 shows the quantile regression coefficients (dark blue lines) with their 95\% CIs for the associations between the U5MR and four socioeconomic factors.

The fixed-effects model showed that, on average, the GDP per capita was negatively correlated with the U5MR. However, this model did not give a complete picture of this association. When we used the quantile fixed-effects model, the GDP per capita was negatively associated with the U5MR at all quantiles of the U5MR distribution. All of these regression coefficients showed a slightly decreasing trend (from low to high quantiles of the U5MR distribution), while the negative association between the U5MR and the GDP per capita was stronger for higher quantiles of the U5MR distribution; for example, the 10th percentile estimate of the U5MR was $-0.52(95 \% \mathrm{CI}=-0.81$ to $0.23)$ while the 90th percentile estimate was $-0.84(95 \%$ $\mathrm{CI}=-1.22$ to -0.45 ) (Figure $4 \mathrm{~A}$ ).

The fixed-effects model also showed that, on average, the GDP growth rate was positively correlated with the U5MR. The quantile fixed-effects model indicated that the increasing trend was statistically significant only for the 50th, 75th, and 90th percentiles (Figure 4B).

The fixed-effects model showed that, on average, inflation was positively correlated with the U5MR. According to the quantile fixed-effects model, inflation was positively associated with the U5MR for all five quantiles of the U5MR distribution with an increasing tendency; for example, the 10th percentile estimate of the U5MR was 0.15 

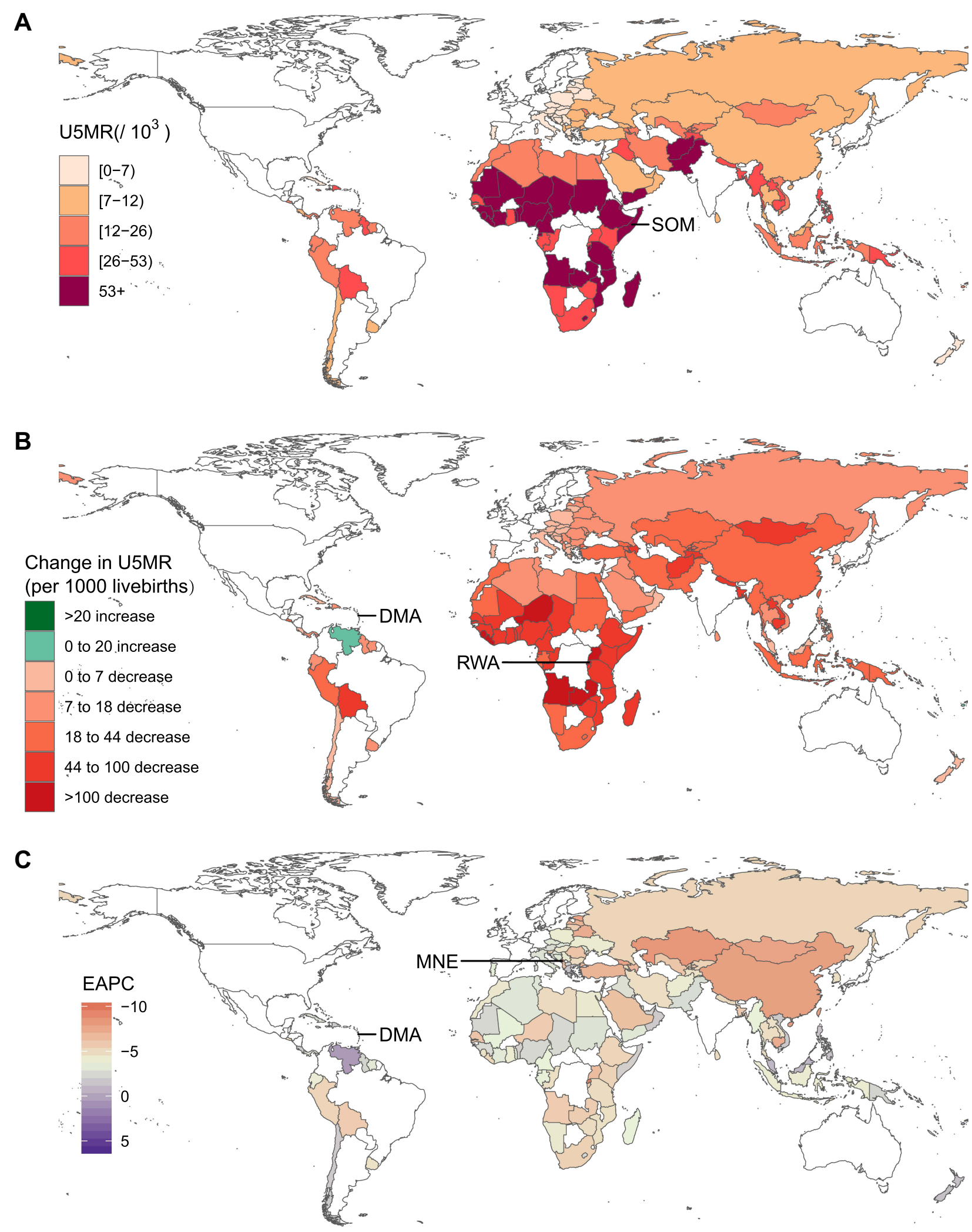

Figure 2 The burden of U5MR in 137 BRI countries. (A) U5MR in 2018; (B) The relative change in U5MR between 2000 and 2018; (C) The estimated annual percentage change of U5MR from 2000 to 2018.

Abbreviations: U5MR, under-five mortality rate; BRI, Belt and Road innovation; SOM, Somalia; MNE, Montenegro; RWA, Rwanda; DMA, Dominica. 


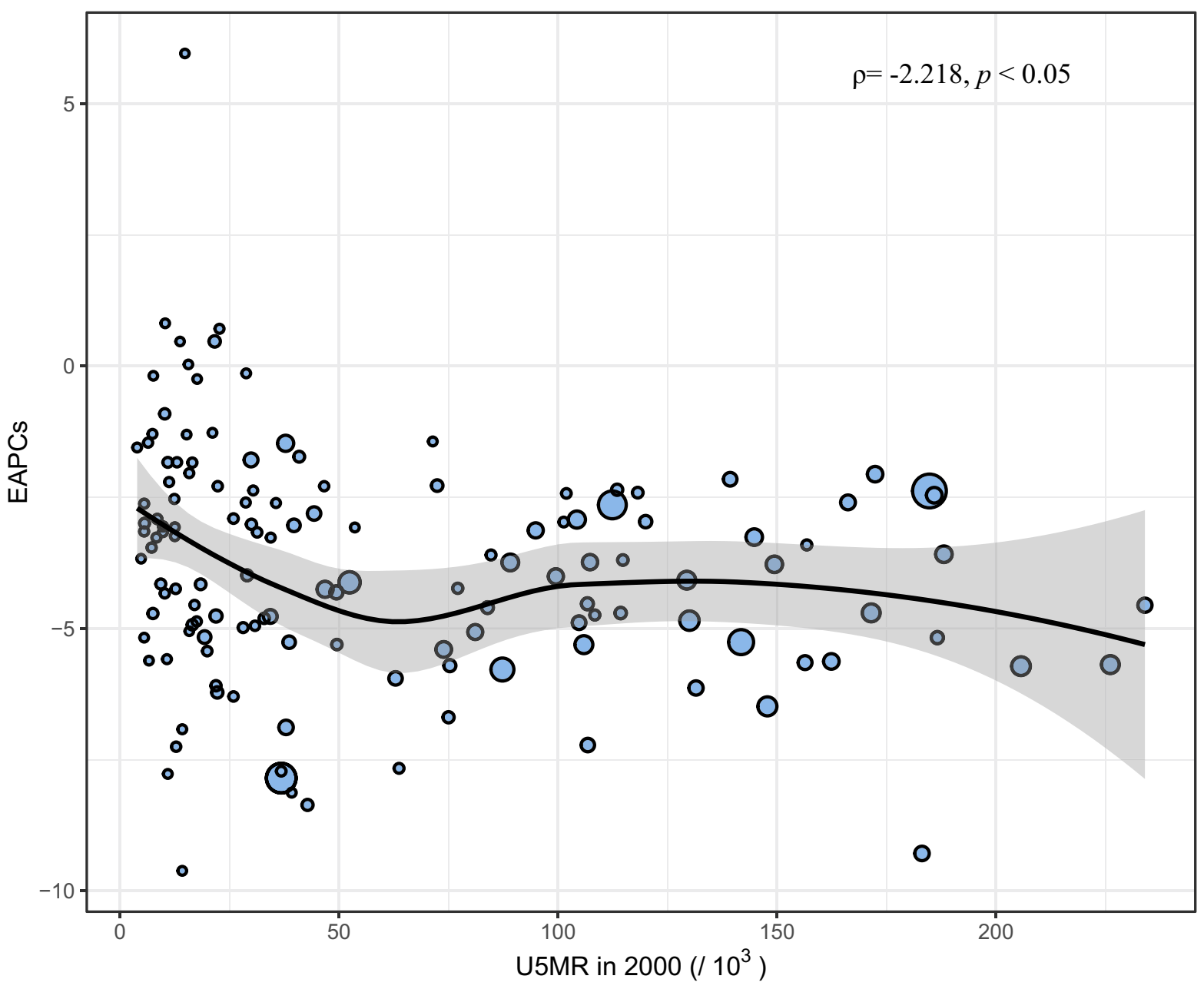

Number of under-five deaths $\bigcirc 250000 \bigcirc 500000 \bigcirc 750000$

Figure 3 The correlation between EAPC and U5MR in 2000 in I 37 BRI countries. The size of circle is increased with the cases of number of under-five deaths. The $\rho$ indices and $p$ were derived from Pearson's product-moment correlation analysis.

Abbreviations: EAPC, estimated annual percentage change; U5MR, under-five mortality rate; BRI, Belt and Road innovation.

$(95 \% \mathrm{CI}=0.06$ to 0.24$)$ while the 90 th percentile estimate was $0.41(95 \% \mathrm{CI}=0.19$ to 0.64$)$ (Figure $4 \mathrm{C})$.

Finally, the fixed-effects model showed that the unemployment rate was positively correlated with on the U5MR, while the quantile fixed-effects model suggested that this relationship was statistically significant for only some of the quantiles (eg, the 10th percentile) (Figure 4D).

\section{Discussion}

This study examined the U5MR burden and its related correlating socioeconomic factors among BRI countries. The U5MR generally decreased from 2000 to 2018 in most BRI countries, but the temporal trends varied markedly between individual countries. How the socioeconomic factors of the GDP per capita, annual percentage growth rate of GDP, inflation, and unemployment rate correlated the U5MR was related to the distribution of the U5MR.

In 2018, the U5MR was highest in certain sub-Saharan African BRI countries (ie, Somalia, Nigeria, and Chad). The high rates of poverty and inequity ${ }^{26}$ in Sub-Saharan Africa result in this region having the highest global burden of under- 5 deaths. The SDG require all countries to reduce the U5MR to no more than 25 per 1000 live births by $2030 .{ }^{1}$ Although achieving the SDG in sub-Saharan Africa BRI countries will be challenging, two-thirds of the under-5 deaths in Africa are attributable to preventable causes such as pneumonia, diarrhea, and malaria. Therefore, effective interventions will significantly improve the health of children in this region, including 
Table I Association Between U5MR and Socioeconomic Factors in BRI Countries

\begin{tabular}{|c|c|c|c|c|c|c|c|}
\hline & & $\begin{array}{c}\text { I0th } \\
\text { Percentile }^{a}\end{array}$ & $\begin{array}{c}\text { 25th } \\
\text { Percentile }^{a}\end{array}$ & $\begin{array}{c}\text { 50th } \\
\text { Percentile }^{\mathrm{a}}\end{array}$ & $\begin{array}{c}\text { 75th } \\
\text { Percentile }^{\mathrm{a}}\end{array}$ & $\begin{array}{c}\text { 90th } \\
\text { Percentile }^{\mathrm{a}}\end{array}$ & $\begin{array}{c}\text { Fixed Effect } \\
\text { Model }^{\text {b }}\end{array}$ \\
\hline \multirow[t]{3}{*}{ GDP per capita/ $1000^{d}$} & Coefficient ${ }^{c}$ & -0.52 & -0.58 & -0.62 & -0.70 & -0.84 & -0.60 \\
\hline & $95 \% \mathrm{Cl}$ & $-0.81,-0.23$ & $-0.84,-0.32$ & $-0.89,-0.36$ & $-1.00,-0.40$ & $-1.22,-0.45$ & $-0.92,-0.28$ \\
\hline & $\mathrm{p}$-value & $<0.01$ & $<0.01$ & $<0.01$ & $<0.01$ & $<0.01$ & $<0.01$ \\
\hline \multirow[t]{3}{*}{ GDP growth rate (\%) } & Coefficient $^{c}$ & 0.03 & 0.12 & 0.17 & 0.33 & 0.45 & 0.21 \\
\hline & $95 \% \mathrm{Cl}$ & $-0.32,0.37$ & $-0.09,0.32$ & $0.01,0.32$ & $0.06,0.60$ & $0.07,0.83$ & $0.10,0.32$ \\
\hline & $\mathrm{p}$-value & 0.88 & 0.26 & 0.03 & 0.02 & $<0.01$ & $<0.01$ \\
\hline \multirow[t]{3}{*}{ Inflation (\%) } & Coefficient $^{c}$ & 0.15 & 0.14 & 0.21 & 0.33 & 0.41 & 0.20 \\
\hline & $95 \% \mathrm{Cl}$ & $0.06,0.24$ & $0.06,0.22$ & $0.14,0.27$ & $0.19,0.47$ & $0.19,0.64$ & $0.16,0.25$ \\
\hline & $\mathrm{p}$-value & $<0.01$ & $<0.01$ & $<0.01$ & $<0.01$ & $<0.01$ & $<0.01$ \\
\hline \multirow[t]{3}{*}{ Unemployment rate (\%) } & Coefficient $^{c}$ & 0.63 & 0.40 & 0.36 & 0.33 & 0.25 & 1.26 \\
\hline & $95 \% \mathrm{Cl}$ & $0.13,1.14$ & $-0.07,0.87$ & $-0.14,0.85$ & $-0.32,0.98$ & $-0.48,0.98$ & $0.97, I .55$ \\
\hline & $\mathrm{p}$-value & 0.01 & 0.09 & 0.16 & 0.31 & 0.50 & $<0.01$ \\
\hline
\end{tabular}

Notes: ${ }^{a}$ Quantile fixed effects model, the dependent variable was five percentiles (10th, 25th, 50th, 75th, 90th) of the distribution of U5MR. County was used as a classification and the socioeconomic variable (GDP per capita, GDP growth rate, inflation, and unemployment rate) as continuous predictors; ${ }^{\mathrm{b}}$ Fixed effected model, the dependent variable was U5MR. Countries was used as a classification prediction and the socioeconomic factors as continuous predictors; ${ }^{\mathrm{C}}$ The coefficient represents the change in the value at the nth percentile of U5MR unit change in the independent variable; ${ }^{\mathrm{d}}$ Aggregates are based on constant 2010 US dollars.

Abbreviations: U5MR, under-five mortality rate; BRI, Belt and Road innovation.

expanding educational opportunities, improving living and working conditions, and increasing access to satisfactory water and sanitation facilities. ${ }^{26}$

Decreases in the U5MR during 2000-2018 may be partly due to improvements in public-health and healthcare services in the analyzed countries. Rwanda showed the largest absolute decrease in the U5MR and one of the largest decreasing trends among BRI countries. The efforts made in Rwanda to implement major reforms in the health-care sector, investments in the health-care workforce, increased immunization coverage, and increased exclusive breastfeeding have resulted in the secondlargest improvements in children's lives over the past 2 decades. ${ }^{27}$ This success in decreasing the U5MR in Rwanda suggests how child health could also be promoted in countries with higher U5MRs.

Overall, the U5MR decreased in 132 of 137 BRI countries. Among the five other countries, Dominica has had the largest gains and increasing trend in the U5MR. The world has witnessed accelerating mean annual reductions in child mortality over the past 2 decades, and Dominica is the only country in recorded history where child mortality has been increasing consistently over the past 15 years. ${ }^{28}$ Previous studies have indicated that the increase in intrapartum complications are almost exclusively responsible for the increase in neonatal mortality in Dominica, ${ }^{28}$ which accounted for more than $35 \%$ of deaths in 2016 . There are no other countries in the world where intrapartum complications constitute more than $13 \%$ of deaths in children aged less than 5 years. ${ }^{28}$ Therefore, addressing intrapartum complications would be an effective way to reduce the U5MR in Dominica.

In addition, we found that the magnitude of the U5MR variations (namely the EAPC) between 2000 and 2018 was significantly negatively associated with the baseline U5MR among the countries. The U5MR was more likely to decrease over time in those countries with higher U5MRs in 2000, which might be explained by a higher baseline U5MR being associated with (1) larger U5MR variations and (2) easier in controlling the U5MR. These results suggest that given that resources are always limited, focusing on countries with higher U5MRs may be the most-efficient way to reduce the global burden of child mortality.

Country-level determinants of the U5MR have been studied extensively, ${ }^{8,17,29}$ with national income being the most widely acknowledged factor. GDP per capita is an important indicator of a country's income, ${ }^{18}$ previous studies have proved that higher-income at the country level correlates closely with better health outcomes for that country's population. ${ }^{17}$ This phenomenon not only observed in developed countries (on average, a 1\% decrease in per capita GDP results in an increase in infant mortality of between 0.24 and 0.40 per 1000 children born), ${ }^{30}$ but also found in developing countries (if a country has an infant mortality of 50 per 1000 


\section{A}



\section{B}

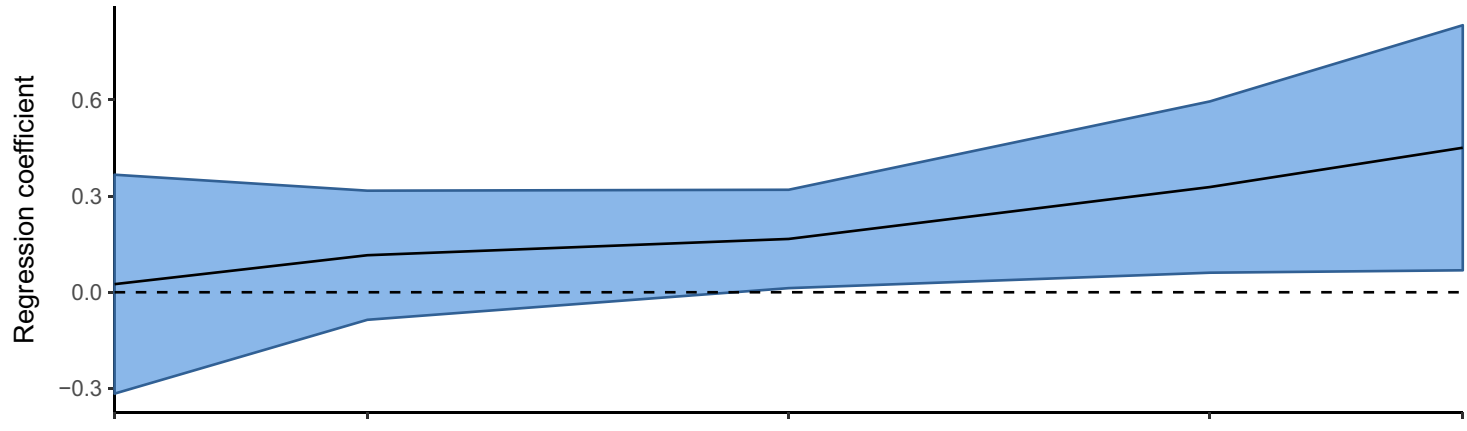

C



D

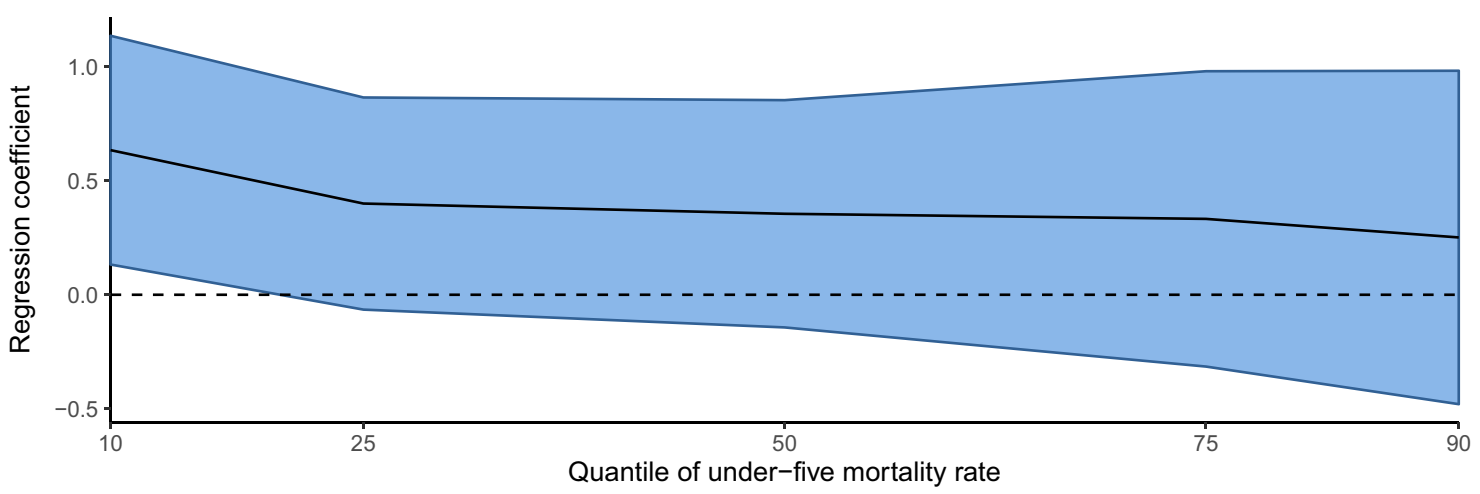

Figure 4 Quantile regression coefficients for U5MR and socioeconomic factors on percentiles of total U5MR in BRI countries. This picture shows the quantile regression coefficients (dark blue line) with $95 \% \mathrm{Cl}$ for the relationship between U5MR and socioeconomic factors. (A) Quantile regression coefficients for GDP per capita and U5MR on percentiles of total U5MR; (B) Quantile regression coefficients for GDP growth rate and U5MR on percentiles of total U5MR; (C) Quantile regression coefficients for inflation and U5MR on percentiles of total U5MR; (D) Quantile regression coefficients for unemployment rate and U5MR on percentiles of total U5MR. Abbreviations: U5MR, under-five mortality rate; BRI, Belt and Road innovation. 
live births, GDP per capita purchasing power parity increases by $10 \%$, the infant mortality will decrease to 45 per 1000 live births). ${ }^{17}$ Consistent with previous studies, our findings indicate that the U5MR was directly associated with the GDP per capita. An increasing GDP per capita will result in healthcare systems having more resources to provide better services and also increase overall living standards, ${ }^{17}$ which together would contribute to improving child health. Futher more, our study provided an interesting finding that the impact of the GDP per capita on child health was not consistent in countries with different U5MR levels, with the identified negative correlation being stronger in countries with higher U5MRs. This indicates that the improvements in child health induced by increases in income may be greater in countries with higher U5MRs. This may be because countries with higher U5MR have more room for improvement in U5MRs, and the increase in income in countries with higher U5MRs can easily reduce child malnutrition through improved nutrition, thus reducing child mortality.

A study of low- and middle-income countries shows that the contribution of economic growth to the reduction in early childhood undernutrition in developing countries is very small to null, ${ }^{31}$ research from India also confirms this view. ${ }^{32}$ Child malnutrition is directly related to child mortality. ${ }^{33}$ However, some studies have concluded that the association between economic growth and child malnutrition is strong and significant. ${ }^{19}$ In this study, we found that the U5MR was positively associated with the GDP growth rates only in countries with higher U5MRs, furthermore, with the effect gradually decreasing and finally disappearing as the U5MR decreased. This positive association can be partly explained by so-called creative destruction, ${ }^{34}$ which refers to short-term damage to health caused by economic growth. Rapid increases in the economic situation lead to increases in overall workloads and their intensities, which are important risk factors for injury and cardiovascular disease. ${ }^{34}$ In addition, rapid economic growth also leads to undesirable increases in alcohol, tobacco, and calorie intakes, which not only affect the health of adults but also has certain impacts on child health. ${ }^{35}$ In this study, we did not found a correlation between U5MR and GDP growth rates in countries with lower U5MR. Most countries with lower U5MR among BRI were wealthy countries, they may provide sufficient support to improve child health, which makes short-term macroeconomic fluctuations have little impact on children's health in these countries. Although GDP growth rates seem to increase the U5MR over the short term in countries with higher U5MRs, in the long run GDP growth was found to be beneficial to child health. ${ }^{34}$ These benefits was be found in the United State many years ago, that rapid economic growth increased deaths in the short term, but was a central factor in the decline of mortality in the United States during the 20th century in the long term. ${ }^{34}$ Theoretically, economic growth can enable governments to provide better public-health systems and invest in infrastructure that directly or indirectly improves health, such as by providing improved water and sanitation facilities as well as universal immunization cover. $^{36}$

Inflation was previously found to be an important socioeconomic factor that is strongly associated with health. ${ }^{37}$ Previous studies have shown that, inflation can lead to increased undernutrition in the poorest countries, which can lead to increased infant and child mortality. ${ }^{23}$ The present study similarly found a positive association between inflation and the U5MR in BRI countries. This positive correlation can be partly explained by increasing food prices due to inflation adversely affecting the quality of the diet, including the micronutrient intake, which would adversely impact child health. ${ }^{23}$ In addition, inflation will increase the cost of medical services, ${ }^{37}$ which would further impact child health. Inflation seems to have a greater impact on the U5MR in countries with higher U5MRs, which can be at least partly explained by most countries with high U5MRs being less developed. The food available in these countries is more dependent on imports and constitutes a greater share of the household expenditure, making people more sensitive to prices. ${ }^{23}$ However, although inflation may have some impact on child health, a certain level of inflation is good for economic development, ${ }^{38}$ which in turn can promote child health. ${ }^{17}$ From a public-health perspective, keeping inflation at an appropriate level seems a suitable strategy for promoting child health.

Unemployment has pronounced negative effects on the life situation of an individual, several studies have shown an increased risk of early mortality among the unemployed. ${ }^{39}$ Previous studies have found that unemployment can increase child neglect because it reduces parental access to the resources required to provide for the basic needs of a child such as clothing, food, and medical care. ${ }^{40} \mathrm{We}$ found that the unemployment rate only impacts the U5MR in BRI countries with lower U5MRs. Among countries with higher U5MRs, the main cause of child mortality is infectious diseases including pneumonia, diarrhea, and malaria. ${ }^{2}$ The implementation of a series of effective and low-cost preventive and therapeutic interventions including breastfeeding promotion, improved water and sanitation facilities, vaccines, and 
public-health advertisements has resulted in the U5MR in such countries declining rapidly in recent years. ${ }^{2}$ This high rate of decline may mask the impact of unemployment on the U5MR. Countries with lower U5MRs have already made substantial progress toward reducing child mortality. Although there is still room for improvement in these countries, the difficulty of reducing child mortality has increased, ${ }^{2}$ which may reveal the previously masked impact of the unemployment rate on child deaths.

This study was subject to some limitations. First, we analyzed data over a relatively short time span. Collecting more data over a longer period would provide a better understanding of the trends in the U5MR and the correlations between the U5MR and socioeconomic variables. Second, this study had an ecological design that made it impossible to identify causal relationships.

\section{Conclusion}

This study has extended the literature on the global-health component of the BRI by documenting the U5MR burden among BRI countries, and analyzing the relationships between various socioeconomic factors and different quantiles of the U5MR. The results of the study show that the U5MR declined between 2000 and 2018 in most BRI countries, with the magnitude and speed of the reductions varying across countries. Countries with higher U5MRs in 2000 experienced more rapid decreases in the U5MR from 2000 to 2018. Some BRI countries still had high U5MRs in 2018, and so further substantial efforts will be required to achieve the SDG by 2030. Effective interventions including expanding access to education, increasing investment in health care workers, improving immunization coverage, increasing exclusive breastfeeding levels, improving living and working conditions, controlling complications during childbirth, and increasing access to improved water and sanitation facilities will improving the health of children in the area to some extent.

The correlation of socioeconomic factors and the U5MR was related to the distribution of the U5MR. The U5MRs in BRI countries with higher U5MRs were affected more by the GDP per capita, inflation, and GDP growth rate. The U5MRs in BRI countries with lower U5MRs were affected more by the unemployment rate. Although the relationships between socioeconomic factors and the U5MR appear to be complex, improving the economic situation will undoubtedly benefit child health in BRI countries in the long run. Based on the impact of economic status on child health in this study, we argue that improvements in economic status associated with
BRI are an important opportunity to improve child health in these countries. Not only for those working in the health field, but also for national policymakers, promoting higher national income levels and job opportunities through growth in international trade can effectively improve the nation's infrastructure and raise people's living standards, which should be an effective way to reduce the global burden of child mortality.

\section{Acknowledgments}

The work was financially supported by Jiangsu Province Postdoctoral Research Funding Scheme (2021k548C). We thank all those who have contributed to this manuscript.

\section{Disclosure}

The authors report no conflicts of interest in this work.

\section{References}

1. United Nations. UN Sustainable Development Goals; 2018. Available from: https://www.un.org/development/desa/disabilities/envi sion2030-goal3.html. Accessed April 10, 2020.

2. Liu L, Oza S, Hogan D, et al. Global, regional, and national causes of under-5 mortality in 2000-15: an updated systematic analysis with implications for the Sustainable Development Goals. Lancet. 2016;388(10063):3027-3035. doi:10.1016/S0140-6736(16)31593-8

3. Wang H, Liddell CA, Coates MM, et al. Global, regional, and national levels of neonatal, infant, and under-5 mortality during 1990-2013: a systematic analysis for the Global Burden of Disease Study 2013. Lancet. 2014;384(9947):957-979. doi:10.1016/S01406736(14)60497-9

4. Hu R, Liu R, China's Belt HN. Road Initiative from a global health perspective. Lancet Glob Health. 2017;5(8):e752-e753. doi:10.1016/ S2214-109X(17)30250-4

5. Tang K, Li Z, Li W, China's Silk CL. Road and global health. Lancet. 2017;390(10112):2595-2601. doi:10.1016/S0140-6736(17)32898-2

6. Bai R, Wei J, An R, et al. Trends in life expectancy and its association with economic factors in the belt and road countries-evidence from 2000-2014. Int J Environ Res Public Health. 2018;15(12):2890. doi:10.3390/ijerph15122890

7. Chen J, Bergquist R, Zhou XN, Xue JB, Qian MB. Combating infectious disease epidemics through China's Belt and Road Initiative. PLoS Negl Trop Dis. 2019;13(4):e0007107. doi:10.1371/ journal.pntd.0007107

8. Ensor T, Cooper S, Davidson L, Fitzmaurice A, Graham WJ. The impact of economic recession on maternal and infant mortality: lessons from history. BMC Public Health. 2010;10:727. doi:10.11 86/1471-2458-10-727

9. Hanf M, Nacher M, Guihenneuc C, Tubert-Bitter P, Chavance M. Global determinants of mortality in under 5s: 10 year worldwide longitudinal study. BMJ. 2013;347:f6427. doi:10.1136/bmj.f6427

10. Condliffe S, Link CR. The Relationship between Economic Status and Child Health: evidence from the United States. Am Econ Rev. 2008;98(4):1605-1618. doi:10.1257/aer.98.4.1605

11. Aber JL, Bennett NG, Conley DC, Li J. The effects of poverty on child health and development. Annu Rev Public Health. 1997; 18:463-483. doi:10.1146/annurev.publhealth.18.1.463

12. WHO. Children: improving survival and well-being; 2020. Available from: https://www.who.int/news-room/fact-sheets/detail/childrenreducing-mortality. Accessed September 18, 2021. 
13. Geraci M, Bottai M. Linear quantile mixed models. Stat Comput 2014;24(3):461-479. doi:10.1007/s11222-013-9381-9

14. Belt and Rroad Portal. List of countries that have signed cooperation documents with China to jointly build the "Belt and Road"; 2020 Available from: https://www.yidaiyilu.gov.cn/gbjg/gbgk/77073.htm. Accessed April 12, 2020.

15. Van Malderen C, Amouzou A, Barros AJD, Masquelier B, Van Oyen H, Speybroeck N. Socioeconomic factors contributing to under-five mortality in sub-Saharan Africa: a decomposition analysis. BMC Public Health. 2019;19(1):760. doi:10.1186/s12889-019-7111-8

16. Fountoulakis KN, Kawohl W, Theodorakis PN, et al. Relationship of suicide rates to economic variables in Europe: 2000-2011. $\mathrm{Br}$ J Psychiatry. 2014;205(6):486-496. doi:10.1192/bjp.bp.114.147454

17. O'Hare B, Makuta I, Chiwaula L, Bar-Zeev N. Income and child mortality in developing countries: a systematic review and meta-analysis. J R Soc Med. 2013;106(10):408-414. doi:10.1177/ 0141076813489680

18. Egger G, Swinburn B, Islam FM. Economic growth and obesity: an interesting relationship with world-wide implications. Econ Hum Biol. 2012;10(2):147-153. doi:10.1016/j.ehb.2012.01.002

19. O'Connell SA, Smith C. Economic growth and child undernutrition. Lancet Glob Health. 2016;4(12):e901-e902. doi:10.1016/S2214109X(16)30250-9

20. Lin YC, Chang YH, Yan HT. Is trade a blessing or a curse? A panel data analysis of the determinants of depressive disorders. Int $J$ Public Health. 2020;65(7):1113-1121. doi:10.1007/s00038-020-01410-6

21. Pieters J, Rawlings S. Parental unemployment and child health in China. Rev Econ Househ. 2020;18(1):207-237. doi:10.1007/s11150019-09457-y

22. Arndt C, Hussain MA, Salvucci V, Østerdal LP. Effects of food price shocks on child malnutrition: the Mozambican experience 2008/2009. Econ Hum Biol. 2016;22:1-13. doi:10.1016/j.ehb.2016.03.003

23. Lee HH, Lee SA, Lim JY, Park CY. Effects of food price inflation on infant and child mortality in developing countries. Eur $J$ Health Econ. 2016;17(5):535-551. doi:10.1007/s10198-015-0697-6

24. Liu Q, He H, Yang J, Feng X, Zhao F, Lyu J. Changes in the global burden of depression from 1990 to 2017: findings from the Global Burden of Disease study. J Psychiatr Res. 2019;2:545.

25. Bottai M, Cai B, McKeown RE. Logistic quantile regression for bounded outcomes. Stat Med. 2010;29(2):309-317. doi:10.1002/ $\operatorname{sim} .3781$

26. Kinney MV, Kerber KJ, Black RE, et al. Sub-Saharan Africa's mothers, newborns, and children: where and why do they die? PLoS Med. 2010;7(6):e1000294. doi:10.1371/journal.pmed.1000294

27. Save the Children. Global Childhood Report 2019: changing lives in our lifetime; 2020. Available from: https://resourcecentre.savethechil dren.net/library/global-childhood-report-2019-changing-lives-ourlifetime. Accessed April 11, 2020.

28. Naderkhani G, Oyefolu O, Ali M, Gunawardana D, Mahailet C, Massicotte A. The national tragedy of rising childhood mortality in Dominica: 15 years and counting. Lancet Global Health. 2019;7(11): e1497-e1498. doi:10.1016/S2214-109X(19)30344-4
29. Bishai DM, Cohen R, Alfonso YN, Adam T, Kuruvilla S, Schweitzer J. Factors Contributing to Maternal and Child Mortality Reductions in 146 Low- and Middle-Income Countries between 1990 and 2010. PLoS One. 2016;11(1):e0144908. doi:10.1371/journal. pone. 0144908

30. Erdoğan E, Ener M, Arıca F. The strategic role of infant mortality in the process of economic growth: an application for high income OECD Countries. Procedia Soc Behav Sci. 2013;99:19-25. doi:10.1016/j.sbspro.2013.10.467

31. Vollmer S, Harttgen K, Subramanyam MA, Finlay J, Klasen S, Subramanian SV. Association between economic growth and early childhood undernutrition: evidence from 121 Demographic and Health Surveys from 36 low-income and middle-income countries. Lancet Glob Health. 2014;2(4):e225-234. doi:10.1016/S2214-109X (14)70025-7

32. Subramanyam MA, Kawachi I, Berkman LF, Subramanian SV. Is economic growth associated with reduction in child undernutrition in India? PLoS Med. 2011;8(3):e1000424. doi:10.1371/journal.pmed. 1000424

33. Pelletier DL, Frongillo EA Jr, Schroeder DG, Habicht JP. The effects of malnutrition on child mortality in developing countries. Bull World Health Organ. 1995;73(4):443-448.

34. Brenner MH. Commentary: economic growth is the basis of mortality rate decline in the 20th century-experience of the United States 1901-2000. Int J Epidemiol. 2005;34(6):1214-1221. doi:10.1093/ ije/dyi146

35. Sterling T, Rosenbaum W, Weinkam J. Income, race, and mortality. J Natl Med Assoc. 1993;85(12):906-911.

36. Lange S, Vollmer S. The effect of economic development on population health: a review of the empirical evidence. $\mathrm{Br}$ Med Bull. 2017;121(1):47-60. doi:10.1093/bmb/ldw052

37. Virts JR, Wilson GW. Inflation and health care prices. Health Aff. 1984;3(1):88-100. doi:10.1377/hlthaff.3.1.88

38. Williams C, Gilbert BJ, Zeltner T, Watkins J, Atun R, Maruthappu M. Effects of economic crises on population health outcomes in Latin America, 1981-2010: an ecological study. BMJ Open. 2016;6(1): e007546. doi:10.1136/bmjopen-2014-007546

39. Voss M, Nylen L, Floderus B, Diderichsen F, Terry PD. Unemployment and early cause-specific mortality: a study based on the Swedish twin registry. Am J Public Health. 2004;94 (12):2155-2161. doi:10.2105/AJPH.94.12.2155

40. Powdthavee N, Vernoit J. Parental unemployment and children's happiness: a longitudinal study of young people's well-being in unemployed households. Labour Econ. 2013;24:253-263. doi:10. 1016/j.labeco.2013.09.008
International Journal of General Medicine

\section{Publish your work in this journal}

The International Journal of General Medicine is an international, peer-reviewed open-access journal that focuses on general and internal medicine, pathogenesis, epidemiology, diagnosis, monitoring and treatment protocols. The journal is characterized by the rapid reporting of reviews, original research and clinical studies
Dovepress

across all disease areas. The manuscript management system is completely online and includes a very quick and fair peer-review system, which is all easy to use. Visit http://www.dovepress.com/ testimonials.php to read real quotes from published authors. 